\title{
PENDIDIKAN KARAKTER BERBASIS SIRAH NABAWIYAH
}

\author{
Moh. Toriqul Chaer \\ STIT Islamiyah Karya Pembangunan Paron Ngawi \\ Email: toriqul 210874@gmail.com \\ Azizunisak Hidayati Wahyuna \\ STIT Islamiyah Karya Pembangunan Paron Ngawi \\ Email: azizunisak.hw@gmail.com
}

\begin{abstract}
This study seeks to synergize the education of character-based Sirah Nabawiyah. The effort to identify the education-based moral and ethical education theme in Sirah Nabawiyah synergizes with the concept of the liberation character of Paulo Freire. The purpose of education is moral education and the ability to cultivate a liberation spirit of inequality and social discrimination in the community. This study is library research, a literary search related to the thought of Freire and the concept of Sirah Nabawiyah. This research is also included in the category of historical-factual research because the one that is research is the history of one's thinking. The results of the study found: firstly, education, according to Freire, must be able to adapt to the pace of reality, to remain in the state of being. Second, the education learning of the liberation-based character Sirah Nabawiyah rests on ethical values, perceives and loves the goodness manifested in the advocacy effort of the suppression and oppression situation. Thirdly, a release-based education based on Sirah Nabawiyah should present a critical, adaptive and integrated attitude. Finally, the hope of the education-based character Sirah Nabawiyah can advocate the problem of cultural concussion by a wise and thoughtful.
\end{abstract}

Key Words: Character Education, Sirah Nabawiyah, The Liberation Paradigm

\section{PENDAHULUAN}

Pendidikan sebagai upaya untuk memberikan solusi perkembangan dan perubahan kemanusiaan secara dinamik dan gradual. ${ }^{1}$ Pendidikan sebagai interaksi

1 Nel Noddings, "Aims, Goals, and Objectives," Educational Theory in a Global and Technological Era 8 (2007): 7-15; Caroline Mansfield and Marold Wosnitza, "Goals for Teaching: Towards a Framework for Examining Motivation of Graduating Teachers," Australian Journal of Educational \& Developmental Psychology 12 (2012): 14; William Gallagher, Proyecto Regional de 
antara manusia dengan lingkungannya termasuk lingkungan alam dan lingkungan manusia. ${ }^{2}$ Pada interaksi tersebut manusia bukan hanya mengusahakan interaksi dengan sesama manusia, namun dengan alamnya sehingga dapat mengembangkan potensi manusia secara optimal. Upaya pendidikan akan berpengaruh secara kualitas dan kuantitas pada sumber daya manusia serta dan upaya peningkatan kesejahteraan dan kemakmuran dalam masyarakat. ${ }^{3}$

Pendidikan dalam Islam merupakan sebuah rangkaian proses pemberdayaan manusia menuju taklif (kedewasaan), baik secara akal, mental maupun moral, untuk menjalankan fungsi kemanusiaan yang diemban-sebagai seorang hamba (abd) dihadapan Khaliq-nya dan sebagai pemelihara (khalifah) pada semesta. ${ }^{4}$

Howard dalam Madjid (2011) berpendapat bahwa pada abad 18 dan 19 pendidikan karakter mulai dipandang sebagai tujuan utama pendidikan, namun timbul tenggelam berkaitan dengan masalah-masalah politik dan kejadian-kejadian bersejarah. Begitu pula di Indonesia, corak pendidikan karakter bersesuaian dengan era politik yang berkuasa. Misalnya pada era demokrasi terpimpin, pendidikan karakter dikenal dengan istilah national and character building. ${ }^{5}$

Indicadores Educativos, and UNESCO, Regional Report: Achieving the Educational Goals (Santiago, Chile: Ministerio de Educación : UNESCO, 2003); Educational Goals: Prep. for the International Bureau of Education, Studies and Surveys in Comparative Education (Paris: Unesco, 1980); Sholeh, Asrorun Niam Sholeh, Membangun Profesionalitas Guru Analisis Kronologis atas Lahirnya UU Guru dan Dosen, (Jakarta: eLSAS, 2006), 3

${ }^{2}$ Saiful Bahri Djamarah, Strategi Belajar Mengajar, (Bandung, Rineka Cipta, 1995). 8.

3 Shofwan and S. A Kuntoro, "Pengelolaan Program Pembelajaran Pendidikan Alternatif Komunitas Belajar Qaryah Thayyibah di Salatiga Jawa Tengah," JPPM (Jurnal Pendidikan Dan Pemberdayaan Masyarakat) 1, No. 1 (2014): 51; Nashar, Peranan Motivasi Dan Kemampuan Awal Dalam Kegiatan Pembelajaran (Jakarta: Delia Press, 2004), 50.

${ }^{4}$ Ahmad Tafsir, Ilmu Pendidikan dalam perspektf Islam, (Bandung: PT. Rosdakarya, 2001), 74; Amanah, "Pendidikan Luar Sekolah (Optimalisasi Fungsi Keluarga sebagai Institusi Pendidikan)", Jurnal Kependidikan, STAIN Samarinda, Vol. VI No. 1 (Juni 2006), 36. Sebagai perbandingan lihat Undangundang Republik Indonesia, Nomor 20 Tahun 2003 tentang Sistem Pendidikan Nasional, Bab 1, Ketentuan Umum Pasal 1 ayat 1.

${ }^{5}$ Abdul Majid dan Dian Andayani, Pendidikan Karakter Perspektif Islam. (Bandung: PT Rosdakarya, 2011). Pembacaan lebih lanjut lihat Fauzan Akmal Firdaus and Akrim Mariyat, "Humanistic Approach In Education According To Paulo Freire," At-Ta'dib 12, no. 2 (December 29, 2017): 25, https://doi.org/10.21111/at-tadib.v12i2.1264.; Mohammad Khatib, Saeid Najafi Sarem, and Hadi Hamidi, "Humanistic Education: Concerns, Implications and Applications," Journal of Language Teaching and Research 4, no. 1 (January 1, 2013): 45-51, https://doi.org/10.4304/jltr.4.1.45-51.; Michael H Berkowitz, "A Humanistic Philosophy of Education as Applied to the Teaching of an Introductory Psychology Course.," Master Theses, 2014, 69.; Lilik Untari, "An Epistemological Review On Humanistic Education Theory," Leksema, Volume 1. Np. 1, 2016, 14; Archana Nath, Ritesh Kumar, 
Gagasan merajut idealisme pendidikan perlu diupayakan, hal ini dikarenakan pendidikan merupakan faktor penting dalam menumbuhkembangkan kemampuan manusia, kapasitas (capability), kepada peserta didik agar dapat melihat realita yang ada dengan pendekatan kontekstual yang membebaskan. Maka gagasan berupa konsep revivalisasi dan revitalisasi pendidikan menjadi penting. Disamping itu pendidikan bertanggungjawab secara moral untuk mempersiapkan generasi-generasi yang independen, bertanggungjawab, empati dan kasih sayang terhadap sesama dalam bingkai pendidikan. Disamping itu upaya menumbuh-kembangkan kreatifitas dan inovatif pada diri pendidik menggali modus-modus baru pengelolaan proses pendidikan tanpa harus mengorbankan nilai-nilai idealisme dari tujuan pendidikan itu sendiri. ${ }^{6}$

\section{METODE PENELITIAN}

Penelitian ini merupakan penelitian kepustakaan (library research), yakni data-data penelitian didapatkan dari studi pustaka atau literatur terkait. Penelitian ini juga termasuk dalam kategori penelitian historis-faktual karena yang diteliti adalah sejarah pemikiran seseorang. ${ }^{7}$ Penelitian ini menggunakan pendekatan studi teks. Menurut Lockyer $(2008)^{8}$, studi teks pada dasarnya merupakan analisis data yang mengkaji teks secara mendalam baik mengenai isi dan maknanya maupun struktur dan wacana. Apa pun yang bisa ditafsir diperlakukan sebagai teks.

And Ajit Kumar Behura, "Global Journal Of Engineering Science And Researches," N.D., 4; Laura ZuccaScott, "Know Thyself: The Importance of Humanism in Education," Volume 8, 2017, 8.

6 Trianto, Pembelajaran Inovatif Berorientasi Konstruktivistik. (Jakarta: Prestasi Pustaka Publisher, 2009).

7 Sj. Baker, Filsafat Kebudayan, (Yogyakarta: Kanisius, 1984), 54. Pembacaan lebih lanjut berkenaan dengan metode penelitian kepustakaan lihat Saran Croos, "Library Research Skills," n.d., 23.; Genevieve Hart and Lynn Kleinveldt, "The Role of an Academic Library in Research: Researchers' Perspectives at a South African University of Technology," South African Journal of Libraries and Information Science 77, no. 1 (January 10, 2011), https://doi.org/10.7553/77-1-65; A Rin, "The Value of Libraries for Research and Researchers," n.d., 68.

8 Sharon Lockyer. (2008). Textual Analysis dalam Lisa M. Given, (ed.), Qualitative Research Methods, London: A SAGE Reference Publication 
Metode Hermeneutik El Fadl $(2003)^{9}$ ikut menjadi rujukan dalam melihat data-data yang sesuai. Bahwa menurut Abou El Fadl pembacaan sebuah teks atau informasi haruslah memperhatikan lima syarat tertentu, yaitu honesty, diligence, comprehensiveness, reasonableness dan self-restraint. Selain itu antara teks, penulis, dan pembaca perlu dilakukan sebuah negosisasi artinya pembacaan sebuah teks perlu memperhatikan kondisi lingkungan dan social-cultural penulis dan budaya yang mempengaruhinya.

\section{PEMBAHASAN}

Shane (1984), mengatakan bahwa pendidikan mampu memberikan kontribusi terhadap perkembangan kebudayaan yang lebih baik (education must shift into the future). ${ }^{10}$ Penguatan pendidikan moral (moral education) atau pendidikan karakter (character education) dalam konteks saat ini merupakan upaya untuk mengatasi krisis moral. ${ }^{11}$

Lickona (1992) berpendapat bahwa watak atau karakter anak dalam hal ini peserta didik dapat dibentuk atau dikenal dengan educating for character yang dibentuk melalui tiga aspek meliputi: moral knowing, moral feeling, dan moral behavior. ${ }^{12}$ Inti dari pendidikan karakter adalah mengembangkan potensi anak didik

${ }^{9}$ Khaled M. Abou El Fadl, Speaking in The God's Name: Islamic Law, Authority, and Women (Oxford: Oneworld Publications, 2003).

10 Paulo Freire, Pendidikan Sebagai Praktek Pembebasan, di Indonesiakan oleh Alouis A. Nugroho. Jakarta: PT. Gramedia, 1984, 39; Paulo Freire, Pedagogy of the Oppressed, 30th anniversary ed (New York: Continuum, 2000).

11 Arnis Silvia, "A Closer Look At Character Education In Indonesia: What Every Educator Should Know," Master of English Education UIN Jakarta, 2010, 13. Pembacaan lebih lanjut lihat Heni Kurniasih, Valentina Y. D. Utari, and Akhmadi, "Character Education Policy and Its Implications for Learning in Indonesia's Education System" (Research on Improving Systems of Education (RISE), November 14, 2018), https://doi.org/10.35489/BSG-RISE-RI_2018/007.; Fathur Rokhman et al., "Character Education for Golden Generation 2045 (National Character Building for Indonesian Golden Years)," Procedia - Social and Behavioral Sciences 141 (August 2014): 1161-65, https://doi.org/10.1016/j.sbspro.2014.05.197; Ahmad Nadhif, "Religious Values In Indonesia's Character Education," Jurnal Pendidikan Islam 27, no. 1 (February 18, 2016): 128, https://doi.org/10.15575/jpi.v27i1.500; Ellectrananda Anugerah Ash-shidiqqi, "The Analysis Of Character Education In Indonesia" 3 (2018): 8.

12 T. Lickona, Educating for Character, (New York: Bantam Books, 1992), 219. Selanjutnya Lickona mengatakan bahwa Aspek konsep moral (moral knowing) mencakup kesadaran moral (moral awarness), pengetahuan nilai moral (knowing moral value), pandangan ke depan (perspective taking), penalaran moral (moral reasoning), pengambilan keputusan (decision making), dan pengetahuan diri 
sebagai pembelajar yang baik (good knower) yang selalu terikat dalam berfikir, merasakan dan bertindak pada nilai-nilai kebaikan. Lebih dari itu untuk lingkungan pendidikan Islam tentu menjadi basis spiritual-goodness Strategi paling efektif adalah mengajar dengan "keteladanan dan inspirasi berbasis moral atau karakter". ${ }^{13}$

Q-Anees dan Hambali (2008) mengungkapkan bahwa setidaknya ada beberapa opsi pendidikan karakter diantaranya; (1) knowing the good, (2) feeling and loving the good, (3) acting the good. Pembelajaran dari aspek knowing the good, feeling and loving the good dan acting the good pembelajar butuh keteladanan (akhlak) yang dicontohkan Rasulullah SAW dalam Sirah Nabawiyah merupakan modal dasar pendidikan karakter peserta didik.

Sirah Nabawiyah yang berisi perincian kisah hidup Rasulullah, yakni asalmuasal, suku dan nasab, dan keadaan masyarakatnya, sebelum beliau dilahirkan. Kemudian berlanjut kepada kelahiran beliau, masa kecil, remaja, dewasa, pernikahan, menjadi Nabi, serta perjuangan-perjuangan beliau dalam menegakkan Islam hingga akhir hayatnya. Pendidikan yang mengajarkan bagaimana sifat Nabi yang memiliki ciri sebagai manusia yang ideal secara spiritual-individual, tetapi juga menjadi pelopor perubahan, membimbing masyarakat ke arah perbaikan dan melakukan perjuangan tanpa henti melawan penindasan harus senantiasa diupayakan. Al-Mubarakfury (2000); menjelaskan bahwa Nabi Muhammad Saw sebagai pembawa ajaran Islam merupakan sosok yang memiliki akhlak yang sangat terpuji. ${ }^{14}$

Salah satu upaya adalah memperkuat basis pembelajaran Sirah Nabawiyah dengan pendidikan karakter berbasis paradigma pembebasan; yaitu pendidikan tentang nilai-nilai yang baik (knowing the good), merasakan dan mencintai kebaikan (feeling and loving the good) yang termanifestasi dalam wujud upaya mengadvokasi

(self knowledge). Aspek sikap moral (moral feeling) meliputi: kata hati (conscience), rasa percaya diri (self esteem), empati (emphaty), cinta kebaikan (loving the good), pengendalian diri (self control), dan kerendahan hati (huminity). Aspek perilaku moral (moral behavior) mencakup: kemampuan (compalance), kemauan (will), dan kebiasaan (habbit).

${ }^{13}$ D. K. Albertus, Pendidikan Karakter Integral. Koran Harian Kompas, 11 Februari , 2010

14 Syaikh Shafiyyur-Rahman Al-Mubarakfury. 2000. "Sirah Nabawiyah", Pustaka Al-Kautsar. Syaikh Shafiyyur-Rahman Al-Mubarakfury adalah seorang ulama kontemporer dari Benares, India dalam bukunya "Sirah Nabawiyah", yang memenangkan juara pertama lomba penulisan sejarah Nabi Muhammad yang diadakan oleh Rabithah al-'Alam al-Islami atau Liga Dunia Islam pada tahun 1976. 
manusia tertindas dari situasi penindasan dan ketertindasan. Manusia dalam hal ini peserta didik harus dibangkitkan kesadarannya sebagai subyek dan bukan objek, ia harus terlibat dalam realitas dan mampu menangkap tema realitas zaman, atau dalam pengertian bahwa peserta didik harus mampu hadir ditengah- tengah masyarakat dengan segenap potensi kreatifitas dan nalar kritisnya. Pada pendidikan berbasis pembebasan harus mengupayakan agar sikap kritis peserta didik terjaga dengan baik dan mampu menyesuaikan diri dan terintegrasi dengan semangat zamannya.

Salah satu tokoh pendidikan pembebasan adalah Paulo Freire. la tokoh pendidikan Brasil dan teoretikus pendidikan yang berpengaruh di dunia. Freire juga dikenal sebagai tokoh pendidikan yang sangat kontroversial. ${ }^{15}$ la menggugat sistem pendidikan yang telah mapan dalam masyarakat Brasil. ${ }^{16}$ Robert W. Pazmiño (1988) mengatakan bahwa secara filosofis, pemikiran Freire banyak dipengaruhi oleh aliran pemikiran Fenomenologi, Personalisme, Eksistensialisme, dan Marxisme. Sebagai tokoh pendidikan, ia dikenal sebagai salah satu tokoh utama Rekonstruksionisme. ${ }^{17}$ Freire mengajukan konsep pendidikan yang disebut dengan "problem posing of education", yaitu pendidikan yang bersifat menghadapkan subjek didik kepada persoalan- persoalan problematik dengan cara berpikir kreatif dan inovatif dalam pemecahannya. ${ }^{18}$

${ }^{15}$ Lihat Hujair AH. Sanaky, Paradigma Pendidikan Islam: Membangun Masyarakat Madani Indonesia (Yogyakarta: Safiria Insania Press, 2003), 8; Abd. Malik Haramain, et.al. Pemikiran-pemikiran Revolusioner (Yogyakarta: Averroes Press, 2001), 158-159.

16 Lihat selengkapnya dalam Denis Colins, Paulo Freire His Life, Works and Thought. (New York: Paulist Press, 1977), 5.

17 Pazmino, Robert. W, Pazmino, Foundational Issues in Christian Education: An Introduction in Evangelical Perspective. Grand Rapids: Baker, 1988, p. 68. Pemikiran Freire ada yang langsung bisa dibaca dari karya-karyanya yang sudah diterjemahkan, tapi ada yang ditulis orang lain. Jenis karya pertama, misalnya, "The Politic of Education: Culture, Power and Liberation (terj.,1999), Pedagogy of the Oppressed (terj, 1985), Educacao Como Pratica da Liberdade (terj. 1984)". Tentang Freire yang ditulis orang lain adalah karya Denis Collins, Paulo Freire; His Life, Works, and Thought, terj. (Yogyakarta: Pustaka Pelajar,1999) dan Siti Murtiningsih, Pendidikan Alat Perlawanan, Teori Pendidikan Radikal Paulo Freire (Yogyakarta: Resist Book, 2004).

18 Walter Omar Kohan, "Paulo Freire e o Valor Da Igualdade Em Educação," Educação e Pesquisa 45 (2019): e201600, https://doi.org/10.1590/s1678-4634201945201600. Pembacaan lebih terkait konsep pemikiran Freire terkait Problem Possing Education, lihat paulo Freire, "Paulo Freire, Critical Pedagogy And The Tasks Of The Critical Scholar/Activist," São Paulo, 2011, 22; Moacir Gadotti and Carlos Alberto Torres, "Paulo Freire: Education for Development: Legacies: Paulo Freire," Development and Change 40, no. 6 (November 2009): 1255-67, https://doi.org/10.1111/j.1467- 
Konsep pedagogis yang demikian didasarkan pada pemahaman bahwa manusia mempunyai potensi untuk berkreasi dalam realitas dan untuk membebaskan diri dari penindasan budaya, ekonomi dan politik. Salah satu prasyarat yang dibutuhkan untuk ketercapaian "problem posing of education" adalah iklim demokratis, dialogis, egaliter, rendah hati, kasih sayang, penuh harapan, kepercayaan dan sikap kritis. ${ }^{19}$

Permasalahan-permasalahan sosial, keagamaan yang tumbuh dan berkembang dimasyarakat menjadi tugas pokok seorang pendidik untuk menterjemahkan, memberikan apresiasi berdasar pada analisa konstekstual, pemahaman, penafsiran yang benar dan proporsional, berimbang kepada peserta didiknya. ${ }^{20}$ Tugas pendidik adalah bagaimana membangun proses empowering peserta didik agar mampu berpikir kritis melakukan perubahan dan perbaikan persoalan hidup menjadi lebih baik (the liberal road to culture). ${ }^{21}$ Pendidikan yang memiliki karakteristik fleksibel (tidak kaku, tidak menolak perubahan, tidak terikat oleh suatu doktrin tertentu), curious (ingin mengetahui, ingin menyelidiki), toleran (egaliter) dan open-minded (mempunyai hati terbuka). ${ }^{22}$

Perlu adanya kontekstualisasi pembelajaran dikelas. Teks yang diajarkan dikelas harus dikaitkan untuk mengadvokasi problematika di kehidupan nyata. Dengan kata lain, harus ada dialektika antara teks dan konteks, teks dan realitas. Dialektika teks dan konteks adalah upaya pembelajaran dengan mengaitkan apa-apa yang telah diajarkan pendidik dengan peristiwa, pikiran atau perasaan yang

7660.2009.01606.x; Timothy Bolin, "Paulo Freire: The Global Legacy," Educational Philosophy and Theory 51, no. 5 (April 16, 2019): 537-39, https://doi.org/10.1080/00131857.2018.1474646; Ana Mami Yamaguchi, "Paulo Freire's Theory of Education in the 1990s:From a Political Struggle to a Social Struggle," n.d., 18; Emmy J Rugut and Ahmed A Osman, "Reflection on Paulo Freire and Classroom Relevance" 2, no. 2 (2013): 6; Sarah Galloway, "Reconsidering Emancipatory Education: Staging A Conversation Between Paulo Freire And Jacques Rancière," Educational Theory 62, no. 2 (April 2012): 163-84, https://doi.org/10.1111/j.1741-5446.2012.00441.x; Yi-Huang Shih, "Rethinking Paulo Freire's Dialogic Pedagogy and Its Implications for Teachers' Teaching," Journal of Education and Learning 7 , no. 4 (May 15, 2018): 230, https://doi.org/10.5539/jel.v7n4p230; Juma E Nyirenda, "The Relevance of Paulo Freire's Contributions to Education and Development in Present Day Africa," n.d., 21.

${ }^{19}$ Schipani, Daniel., Religious Education Encounters Liberation Theology, (Alabama: Religious Education, 1988), 3

${ }^{20}$ Malik, Fajar, Visi Pembaruan Pendidikan Islam, (Jakarta: LP3NI, 1998), 213

${ }^{21}$ Zuhairini, Filsafat Pendidikan Islam, (Jakarta: PT. Bumi Aksara, 2004), 27.

22 H.A.R.Tilaar, Beberapa Agenda Reformasi Pendidikan Nasional dalam Perspektif Abad 21. Magelang: Penerbit Tera Indonesia, 1999, hlm. 116 
diperoleh dari kehidupan rumah, sosial, atletik, musik, seni, rekreasi atau akademik peserta didik. Konsep pembelajaran "bawalah dunia mereka ke dunia kita, dan antarkan dunia kita ke dunia mereka" ini dikenal -juga- sebagai pembelajaran kuantum yang merupakan pengembangan dari teori konstruktivisme. ${ }^{23}$

\section{KESIMPULAN}

Pendidikan bukan hanya sekedar proses penerimaan pengetahuan yang diberikan atau yang diperintahkan orang lain, melainkan ada keterlibatan diri dalam proses pengetahuan, kemajuan kearah raison d'etre realitas. Makin kritis peserta didik menyoroti masa lalu dan masa kini, dalam dan dengan dunianya, atau semakin peserta didik kreatif dan kritis dalam mensiasati hidup memudahkan penyadaran mereka bahwa dunia bukanlah "blind alley". Pembelajaran Sirah Nabawiyah dengan pendidikan karakter berbasis paradigma pembebasan; berbasis nilai-nilai yang baik (knowing the good), merasakan dan mencintai kebaikan (feeling and loving the good) yang termanifestasi dalam wujud advokasi dari situasi penindasan dan ketertindasan. Peserta didik harus dibangkitkan kesadarannya sebagai subyek dan bukan objek. Pada pendidikan karakter berbasis pembebasan berbasis Sirah Nabawiyah harus menghadirkan sikap kritis, adaptif dan terintegrasi. Diperlukan sebuah komitmen moral untuk membangun dunia pendidikan yang humanis, egaliter, kreatif, egaliter dan demokratis dengan mengedepankan nilai- nilai kearifan lokal, sehingga peserta didik tidak menjadi sosok- sosok liyan (terasing) pada lingkungannya.

\section{DAFTAR PUSTAKA}

Albertus, D.K. 2010. Pendidikan Karakter Integral. Dalam koran Harian KOMPAS, 11 Pebruari

Ali, Mukti. 1971. Beberapa Masalah Pendidikan di Indonesia.Yogyakarta: Yayasan Nida

Asari, Hasan. 2008. MA, Etika Akademis dalam Islam. Yogyakarta: Tiara Wacana Ash-Shidiqqi, Ellectrananda Anugerah. "The Analysis Of Character Education In Indonesia" 3 (2018): 8.

${ }^{23}$ http://www.kompas.com/kompas-cetak/0305/05/275458.htm diakses Senin, 8 Juli 2014 
Berkowitz, Michael H. "A Humanistic Philosophy of Education as Applied to the Teaching of an Introductory Psychology Course.," n.d., 69.

Bolin, Timothy. "Paulo Freire: The Global Legacy." Educational Philosophy and Theory 51, no. 5 (April 16, 2019): 537-39. https://doi.org/10.1080/00131857.2018.1474646.

Colins, Denis. 1977. Paulo Freire His Life, Works and Thought. New York: Paulist Press Croos, Saran. "Library Research Skills," n.d., 23.

Educational Goals: Prep. for the International Bureau of Education. Studies and Surveys in Comparative Education. Paris: Unesco, 1980.

Fajar, Malik. 1998. Visi Pembaruan Pendidikan Islam, Jakarta: LP3NI

Firdaus, Fauzan Akmal, and Akrim Mariyat. "Humanistic Approach In Education According To Paulo Freire." At-Ta'dib 12, no. 2 (December 29, 2017): 25. https://doi.org/10.21111/at-tadib.v12i2.1264.

Freire, Paulo. 1984. Pendidikan Sebagai Praktek Pembebasan, di Indonesiakan oleh Alouis A. Nugroho. Jakarta: PT. Gramedia

Freire, Paulo. "Paulo Freire, Critical Pedagogy And The Tasks Of The Critical Scholar/Activist." São Paulo, 2011, 22.

- - - Pedagogy of the Oppressed. 30th anniversary ed. New York: Continuum, 2000.

Fromm, Erich. 1972. Psychoanalysis and Religion, Yale University Press

Gadotti, Moacir, and Carlos Alberto Torres. "Paulo Freire: Education for Development: Legacies: Paulo Freire." Development and Change 40, no. 6 (November 2009): 1255-67. https://doi.org/10.1111/j.14677660.2009.01606.x.

Gallagher, William, Proyecto Regional de Indicadores Educativos, and UNESCO. Regional Report: Achieving the Educational Goals. Santiago, Chile: Ministerio de Educación : UNESCO, 2003.

Galloway, Sarah. "Reconsidering Emancipatory Education: Staging A Conversation Between Paulo Freire And Jacques Rancière." Educational Theory 62, no. 2 (April 2012): 163-84. https://doi.org/10.1111/j.1741-5446.2012.00441.x.

Haramain, Abdul Malik, et.al. 2001, Pemikiran-pemikiran Revolusioner, Yogyakarta: Averroes Press,

Hart, Genevieve, and Lynn Kleinveldt. "The Role of an Academic Library in Research: Researchers' Perspectives at a South African University of Technology." South African Journal of Libraries and Information Science 77, no. 1 (January 10, 2011). https://doi.org/10.7553/77-1-65.

Imron, Ali. 1995. Pembinaan Guru di Indonesia. Jakarta: PT. Dunia Pustaka Jaya

Inkeles. "The Modernization of Man," dalam Weimer (ed). Modernization : The Dynamics of Growth. Voice of Amerika Forum Lectures

Joesoef, Daoed. 2001. "Pembaharuan Pendidikan dan Pikiran", dalam Sularto (ed). Masyarakat Warga dan Pergulatan Demokrasi: Antara Cita dan Fakta. Jakarta: Kompas.

Khaled M. Abou El Fadl. Speaking in The God's Name: Islamic Law, Authority, and Women. Oxford: Oneworld Publications, 2003. 
Khatib, Mohammad, Saeid Najafi Sarem, and Hadi Hamidi. "Humanistic Education: Concerns, Implications and Applications." Journal of Language Teaching and Research 4, no. 1 (January 1, 2013): 45-51. https://doi.org/10.4304/jltr.4.1.45-51.

Kohan, Walter Omar. "Paulo Freire e o Valor Da Igualdade Em Educação." Educação e Pesquisa 45 (2019): e201600. https://doi.org/10.1590/s16784634201945201600.

Kurniasih, Heni, Valentina Y. D. Utari, and Akhmadi. "Character Education Policy and Its Implications for Learning in Indonesia's Education System." Research on Improving Systems of Education (RISE), November 14, 2018. https://doi.org/10.35489/BSG-RISE-RI_2018/007.

Lickona, T. 1992. Educating for Character. New York: Bantam Books.

Mansfield, Caroline, and Marold Wosnitza. "Goals for Teaching: Towards a Framework for Examining Motivation of Graduating Teachers." Australian Journal of Educational \& Developmental Psychology 12 (2012): 14.

Muhaimin. 2002. Paradigma Pendidikan Islam. Bandung: PT. Remaja Rosdakarya

Muhajir, As'aril. 2001. Ilmu Pendidikan Perspektif Kontekstual. Jogjakarta: Ar-Ruzz Media

Murtiningsih, Siti, 2004, Pendidikan Alat Perlawanan, Teori Pendidikan Radikal Paulo Freire, Yogyakarta: Resist Book

Nadhif, Ahmad. "Religious Values In Indonesia's Character Education." Jurnal Pendidikan Islam 27, no. 1 (February 18, 2016): 128. https://doi.org/10.15575/jpi.v27i1.500.

Nath, Archana, Ritesh Kumar, and Ajit Kumar Behura. "Global Journal Of Engineering Science And Researches," n.d., 4.

Noddings, Nel. "Aims, Goals, and Objectives." Educational Theory in a Global and Technological Era 8 (2007): 7-15.

Nyirenda, Juma E. "The Relevance of Paulo Freire's Contributions to Education and Development in Present Day Africa," n.d., 21.

Pazmino, Robert. W. 1988. Foundational Issues in Christian Education: An Introduction in Evangelical Perspective. Grand Rapids: Baker

Rin, A. "The Value of Libraries for Research and Researchers," n.d., 68.

Rokhman, Fathur, M. Hum, Ahmad Syaifudin, and Yuliati. "Character Education for Golden Generation 2045 (National Character Building for Indonesian Golden Years)." Procedia - Social and Behavioral Sciences 141 (August 2014): 116165. https://doi.org/10.1016/j.sbspro.2014.05.197.

Rugut, Emmy J, and Ahmed A Osman. "Reflection on Paulo Freire and Classroom Relevance" 2, no. 2 (2013): 6.

Sanaky, Hujair AH, 2003, Paradigma Pendidikan Islam: Membangun Masyarakat Madani Indonesia Yogyakarta: Safiria Insania Press

Schipani, Daniel. S. 1988. Religious Education Encounters Liberation Theology. Alabama: Religious Education

Sholeh, Asrorun Niam. 2006. Membangun Profesionalitas Guru Analisis Kronologis atas Lahirnya UU Guru dan Dosen. Jakarta: eLSAS 
Shih, Yi-Huang. "Rethinking Paulo Freire's Dialogic Pedagogy and Its Implications for Teachers' Teaching." Journal of Education and Learning 7, no. 4 (May 15, 2018): 230. https://doi.org/10.5539/jel.v7n4p230.

Silvia, Arnis. "A Closer Look At Character Education In Indonesia: What Every Educator Should Know." Master of English Education UIN Jakarta, 2010, 13.

Subagi. 1985. Kritik Atas: Koensientasi dan Pendidikan, Teropong Paulo Freire dan Ivan Illich dalam Martin Sardy (ed). Pendidikan Manusia. Bandung: Alumni

Suyudi. 2005. Pendidikan dalam Perspektif Al-Qur'an. Yogyakarta: Penerbit Mikraj

Syaikh Shafiyyur-Rahman Al-Mubarakfury. 2000. "Sirah Nabawiyah", Pustaka AlKautsar.

Tilaar, H.A.R. 1999. Beberapa Agenda Reformasi Pendidikan Nasional dalam Perspektif Abad 21. Magelang: Penerbit Tera Indonesia

Wahyudi.2006. Pendidikan Islam Berparadigma Pembebasan: Sebuah Solusi Pengembangan Sumber Daya Manusia Menuju Masyarakat Madani, dalam Jurnal Edukasi, Volume 4, Nomor 3, Juli-September, 2006

Untari, Lilik. "An Epistemological Review On Humanistic Education Theory," 2014., 14.

Yamaguchi, Ana Mami. "Paulo Freire's Theory of Education in the 1990s:From a Political Struggle to a Social Struggle," n.d., 18.

Zuhairini, dkk. 2004. Filsafat Pendidikan Islam. Jakarta: PT. Bumi Aksara

Zucca-Scott, Laura. "Know Thyself: The Importance of Humanism in Education," 2018., 8.

Internet

http://www.kompas.com/kompas-cetak/0305/05/275458.htm 